\title{
Growth advantage of CD34+ cells in trisomy 8 high- risk myelodysplastic syndrome despite enhanced apoptotic signals
}

S.R. Youssef, M.M. Ismail, ${ }^{7}$ E. Abd Al Wahed ${ }^{2}$ and H. Al Dessoky²

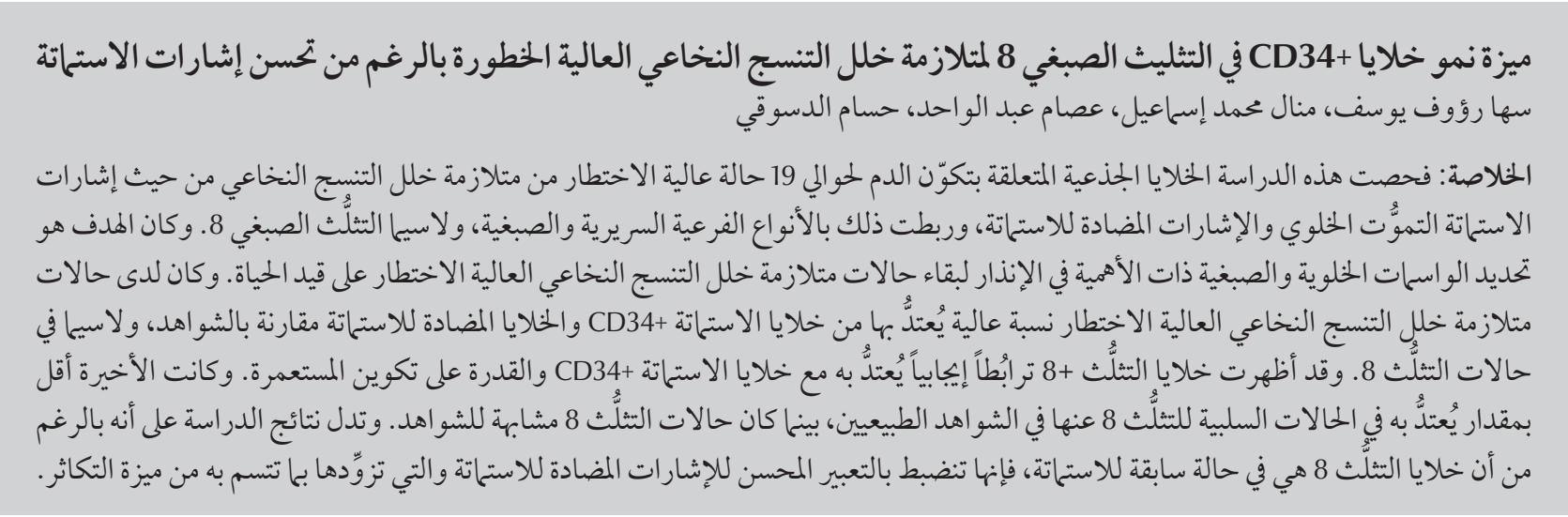

ABSTRACT This study examined haematopoietic stem cells of 19 high-risk cases of myelodysplastic syndrome (MDS) for apoptotic and anti-apoptotic signals and cellular proliferation and correlated these with clinical and cytogenetic subtypes, particularly trisomy 8 . The aim was to identify cellular and cytogenetic markers of prognostic relevance to survival of high-risk MDS cases. High-risk MDS cases had a significantly higher percentage of apoptotic CD34+ cells and anti-apoptotic survivin+ cells than controls, particularly for trisomy 8 cases. Trisomy $8+$ cells showed a significant positive correlation with apoptotic CD34+ cells and capacity for colony formation. The latter was significantly lower in trisomy-8-negative cases than normal controls, while that of trisomy 8 cases was comparable to controls. Our results suggest that although trisomy 8 cells are in a pro-apoptotic state, they are checked by the enhanced expression of anti-apoptotic signals which provide them with their proliferative advantage.

Multiplication des cellules CD34+ dans le syndrome myélodysplasique de haut risque avec trisomie 8 malgré des signaux apoptotiques accrus

RÉSUMÉLaprésenteétudea examinélescellulessoucheshématopoïétiques de19 cas desyndromemyélodysplasique de haut risque à la recherche de signaux apoptotiques et anti-apoptotiques et de proliférations cellulaires et a établi un lien entre ces derniers et les sous-types cytogénétiques et cliniques, en particulier la trisomie 8. L'objectif était d'identifier les marqueurs cellulaires et cytogénétiques pertinents pour le pronostic de survie des cas de syndrome myélodysplasique de haut risque. Une quantification par cytométrie en flux trois couleurs des cellules CD34+/ Annexine+/PI, une analyse FISH, un marquage immunocytochimique des préparations cytospines de la moelle osseuse et des cultures de cellules souches à long terme ont été réalisés. Les cas de syndrome myélodysplasique de haut risque avaient un pourcentage nettement supérieur de cellules CD34+ apoptotiques et de survivine+ antiapoptotiques par rapport aux témoins, en particulier dans les cas atteints de trisomie 8 . Les cellules de trisomie 8+ avaient une corrélation positive importante avec les cellules CD34+ apoptotiques et la capacité à stimuler la formation de colonies. Cette capacité était très inférieure dans les cas négatifs pour la trisomie 8 par rapport aux témoins, alors que dans les cas de trisomie 8, la capacité était comparable à celles des témoins. Nos résultats suggèrent que même si les cellules de trisomie 8 sont à un stade pro-apoptotique, ces dernières sont régulées par l'expression accrue des signaux anti-apoptotiques qui leur permettent de proliférer.

${ }^{2}$ Department of Clinical Pathology; ${ }^{2}$ Department of Internal Medicine, Faculty of Medicine, Ain Shams University, Cairo, Egypt (Correspondence to M.M. Ismail:dr_manalm@hotmail.com).

Received: 23/03/10; accepted: 07/06/10 


\section{Introduction}

Myelodysplastic syndrome (MDS) is a group of clonal stem cell disorders characterized by cytopenias, ineffective haematopoiesis, bone marrow dysplasia and a risk of progression to acute myeloid leukaemia [1]. All patients diagnosed with MDS have a reduced life expectancy compared with ageand sex-matched normal controls, but particularly those patients classified as high-risk of disease [2] using the international prognostic scoring system (IPSS) [3].

The essence of MDS is damage of colony-forming units [4], but the defect of the haematopoietic stem cells is not well characterized. Prior reports have shown that an increase in CD34+ cells, a marker denoting increased blasts in peripheral blood and bone marrow, was associated with poor survival and higher risk of leukaemic transformation in MDS [5]. The effects of cytopenias and leukaemic transformation are the major causes of death in MDS [6].

Apoptosis has a crucial role in MDS, being responsible for the ineffective haematopoiesis that is characteristic of the disease [7]. In previous studies, early MDS was associated with an elevated ratio of apoptosis to cellular proliferation, but the mechanisms of the findings were not then established [8]. In later studies, cases of low-risk MDS showed enhanced intramedullary apoptosis, while high-risk MDS was associated with cellular proliferation, giving the abnormal clone a growth advantage [9]. Survivin, a member of the inhibitor-of-apoptosis family, facilitates cell cycle progression and is found in increased levels in low-risk MDS [7]. However, survivin levels in high-risk MDS and its prognostic impact are still questionable.

Meanwhile, specific cytogenetic abnormalities strongly correlate with prognosis in MDS [10] and about half of patients with primary MDS have cytogenetic abnormalities, the most common of which are trisomy 8 , monosomy 7 and $5 q-[11]$. In trisomy $8+$ MDS, patients suffer predominantly from pancytopenia, and the diagnosis can be confounded by aplastic anaemia since some cases of aplastic anaemia can evolve into trisomy 8+ MDS [12], in which $8+$ appears to confer a favourable prognosis [13]. Chromosomal defects, as grouped by IPSS, and blast cell percentages are so far the most relevant parameters for predicting overall survival and progression-free intervals in MDS [14].

In the current work we examined haematopoietic stem cells of high-risk MDS cases for apoptotic and anti-apoptotic signals, and cellular proliferation as indicated by capacity for colony formation, and correlated these with clinical and cytogenetic subtypes, particularly trisomy 8 . The aim of the study was to identify cellular and cytogenetic markers of prognostic relevance to survival of high-risk MDS cases.

\section{Methods}

\section{Sample}

Bone marrow samples were obtained from 19 high-risk primary MDS patients admitted to the department of haematology, Ain Shams University hospitals, and 10 control subjects free of haematological problems. Approval for the study was obtained from the local ethical committee and participants gave their informed consent for participation.

The 19 cases of high-risk MDS were selected over the 4-year period January 2003 to January 2007 from the total pool of MDS cases ( 76 cases) presenting to the haematology unit during that period.

At the time of sampling all MDS cases were newly diagnosed and had received no previous therapy. The IPSS of each MDS patient was determined according to the definition of Greenberg et al. [15]. The percentage of bone marrow blast cells for estimation of the IPSS score were calculated from average counts performed by 2 experienced haematologists from Leishman stained bone marrow smears and not from flow cytometry quantification of CD34+ cells, since acquiring adequate samples for flow cytometric analysis renders the specimens more dilute than the original smears.

\section{Treatment strategy}

The patients in our study were treated according to standard guidelines for the management of MDS patients [16]. All our patients were of the high-risk group and none of them was eligible for stem cell transplantation. They were treated with intensive chemotherapy using cytarabine $\left(100 \mathrm{mg} / \mathrm{m}^{2} / 24 \mathrm{~h}\right.$ continuous IV infusion) on days 1 to 7 and iadarubicin ( $12 \mathrm{mg} / \mathrm{m}^{2}$ IV bolus) on days 1 to 3 with supportive treatment for associated cytopenias.

\section{Follow-up study}

Follow up was carried out until January 2009 (2 years after the last patient was recruited). Follow up included clinical and laboratory evaluations including regular peripheral blood and bone marrow examinations. The response to therapy was assessed based on the report of the international working group to standardize response criteria for myelodysplastic syndromes [17]. Overall survival was calculated from the time of diagnosis until the last follow up or death, while progression-free survival was defined as the period during which the disease was stable with no hospitalization required.

\section{Data collection}

The following was performed for patients at diagnosis and for controls:

\section{Flow cytometric quantification of ap- optotic CD34+ cells}

Tricolour flow cytometric analysis of erythrocyte-lysed bone marrow specimens (using ammonium chloride 
0.83\%) was performed on Epics-XL (Coulter Electronics) utilizing System II software, version 3.0. Cells were stained with anti-CD34 PC5, Annexin-V FITC and propidium iodide (Becton Dickinson). An isotype matched control was used to exclude non-specific staining. An average of 10000 events was examined in each case. Gated bone marrow blast cells that were positive for CD34 (CD34+) were analysed for apoptosis by staining with Annexin and propidium iodide (thrombin-antithrombin assay). The apoptotic cells were identified as Annexin positive (Annexin+) and propidium iodide negative (PI-), while cells stained with propidium iodide (i.e. necrotic cells) were excluded [10].

\section{Conventional cytogenetic analysis}

Metaphase preparations of bone marrow samples were obtained by setting up short-term cultures with and without phytohaemagglutinin stimulation and exposure to Colcemid" solution (0.1 $\mu \mathrm{g} / \mathrm{mL}$ ) prior to harvesting. At least 10 slides per case were properly aged, banded/counterstained with trypsin/ Giemsa preparation and examined for karyotype abnormalities. At least 20 banded metaphase spreads were counted and interpreted according to the international system for human cytogenetic nomenclature [18].

\section{Quantification of trisomy 8 positive cells by fluorescence in situ hybridi- zation}

Fluorescence in situ hybridization (FISH) was used to qualify the trisomy 8 positive cells. Metaphase and interphase spreads of bone marrow specimens were examined for trisomy 8 using a centromeric probe for chromosome 8 (Vysis Inc.). Cells and probes were simultaneously denatured at $95^{\circ} \mathrm{C}$ then hybridized at $42{ }^{\circ} \mathrm{C}$ overnight. Slides were subsequently washed in 0.4 $x$ saline/sodium citrate (SSC) buffer at $73^{\circ} \mathrm{C}$ for 2 min and $2 \times$ SSC Nonidet P-40 detergent at room temperature for $1 \mathrm{~min}$ then allowed to dry in the dark before counterstaining with 4,6
diamidino-2-phenylindole-II. At least 200 cells were scored per slide and cases were considered positive for trisomy 8 at a cut-off value of $3 \%$ [10].

\section{Quantification of survivin expression} in bone marrow mononuclear cells using immunocytochemistry

Immunocytochemistry methods were used to determine survivin expression in bone marrow mononuclear cells. Using Ficoll-Hypaque density gradient centrifugation, bone marrow mononuclear cells were isolated, washed, their counts adjusted at $1-3 \times 10^{3} / \mathrm{uL}$ and used to prepare cytospin slides on the Cytospin III (Shandon Corp.). Slides were fixed in acetone $100 \%$ for $10 \mathrm{~min}$. at $4{ }^{\circ} \mathrm{C}$ prior to immunostaining for survivin using polyclonal rabbit anti-survivin antibody and the rabbit $A B C$ staining system with the anti-rabbit Ig secondary antibody and avidin biotinylated horseradish peroxidase detection reagent (Santa Cruz Biotechnology). Internal control slides were prepared by replacing the primary antibody with non-immune sera. Slides of controls and cases were mounted, covered and examined under light microscopy. Duplicate slides were evaluated for at least 200 cells for each case, with average counts estimated and positivity established at a cut-off of 5\% [19].

\section{Cell culture for haematopoietic colony} formation and immunophenotyping

Colony forming cell assays were used to quantify colony-forming capacity of haematopoietic progenitors. Then $2 \mathrm{~mL}$ of bone marrow were added to $4 \mathrm{~mL}$ of Dulbecco's modification of Eagle's medium, low glucose containing $10 \%(\mathrm{v} / \mathrm{v})$ heat-inactivated fetal bovine serum and penicillin/streptomycin (Gibco) and centrifuged to pellet the cells and remove the fat layer. Cell pellets were then resuspended and fractionated on a density gradient generated by centrifugation with $70 \%$ Percoll solution at $13000 \mathrm{~g}$ for $20 \mathrm{~min}$. Cells were collected, rinsed with control medium and plated for primary culture. An aliquot of $0.3 \mathrm{~mL}(1-5 \times$ $10^{5} / \mathrm{mL}$ ) of cells were cultured in $3 \mathrm{~mL}$ methyl cellulose based haematopoietic differentiation medium, vortexed and left to stand for $5 \mathrm{~min}$. A aliquot of $1.1 \mathrm{~mL}$ of the cell suspension was put in a low-adherence $35 \mathrm{~mm}$ Petri dish ( $1-5 \times 10^{4}$ cells per dish, 5 dishes per cultured case) then incubated at $37^{\circ} \mathrm{C}$ in a humidified atmosphere with $5 \% \mathrm{CO}_{2}$. The medium was changed every 3 days. After 10 days, adherent cells formed homogeneous colonies. Colonies were enumerated based on morphology recognition in situ by light microscopy and counted per culture. Cells were detached with trypsinEDTA, washed in phosphate-buffered saline, and immediately incubated on ice with labelled mouse anti-human antibodies for determination of CD34 and $\mathrm{CD} 45$, then analysed by flow cytometry [20].

\section{Statistical analysis}

Data analysis was performed using SPSS software, version 10.0. Quantitative data was expressed as mean and standard deviation (SD). Inter-group comparisons were evaluated by Student t-test or Mann-Whitney test. Multiple regression and Spearman correlation were used for quantitative intra-group analysis. Statistical significance was calculated at $P$-value of $<0.05$.

\section{Results}

Table 1 presents the cytogenetic profile and levels of cellular markers as well as survival times for this sample of highrisk MDS patients.

\section{Apoptosis of CD34-positive cells}

A histogram representing the flow cytometric analysis of apoptotic signals in our MDS cases, comparing trisomy $8+$ and 8 - cases is shown in Figure 1. A significantly higher percentage of CD34+/Annexin+/PI- cells was 


\begin{tabular}{|c|c|c|}
\hline \multirow{2}{*}{$\begin{array}{l}\text { Parameter } \\
\text { Cytogenetic profile (by conventional methods) }\end{array}$} & \multicolumn{2}{|c|}{ Value } \\
\hline & No. of patients & $\%$ \\
\hline Normal karyotype & 4 & 21 \\
\hline Monosomy 5 & 1 & 5 \\
\hline Monosomy 7 & 4 & 21 \\
\hline Trisomy 8 & 4 & 21 \\
\hline $20 q^{-}$ & 1 & 5 \\
\hline $5 q^{-}$ & 1 & 5 \\
\hline Failed metaphase & 2 & 11 \\
\hline Complex karyotype & 2 & 11 \\
\hline \multicolumn{3}{|l|}{ Cytogenetic profile (by FISH) } \\
\hline Trisomy 8 & 10 & 53 \\
\hline Cellular marker profile & Mean & SD \\
\hline Blast cells in smears (\%) & 9.0 & 3.0 \\
\hline CD34+ cells by flow cytometry (\%) & 8.0 & 5.5 \\
\hline CD34+/Annexin+/PI- cells (\%) & 30.0 & 25.6 \\
\hline Survivin+ cells (\%) & 10.7 & 13.8 \\
\hline Colony-forming cells (no./culture) & 2180 & 1920 \\
\hline \multicolumn{3}{|l|}{ Patient survival times } \\
\hline Overall survival (months) & 23 & 10 \\
\hline Progression-free survival (months) & 15 & 8 \\
\hline
\end{tabular}

$20 q-=$ deletion of the long arm of chromosome 20,5q-= deletion of the long arm of chromosome 5; FISH=fluorescent in situ hybridization; PI = propidium iodide; SD = standard deviation.

obtained in high-risk MDS cases as compared with normal controls. Also a significantly higher percentage of CD34+/Annexin+/PI- cells was found in trisomy $8+$ cases compared with cases having other cytogenetic abnormalities $(P<0.05)$ (Table 2 and Figure 1).

A significant positive correlation was found between the percentage of CD34+/Annexin+/PI- cells and the percentage of trisomy $8+$ cells $(P<$ $0.05)$ (Figure 2). There was no significant correlation between the percentage of apoptotic cells and survivin + cells or haematopoietic colony counts $(P>$ 0.05) [data not shown].

\section{Cytogenetic findings in high- risk MDS cases}

Using conventional cytogenetics 17/19 (89\%) successful metaphases were obtained, showing 4/19 cases (21\%) with normal karyotype, $4 / 19$ cases (21\%) with trisomy $8,1 / 19$ case $(5 \%)$ with
$20 \mathrm{q}-$, 4/19 cases (21\%) with monosomy $7,2 / 19$ cases (11\%) with both monosomy 7 and 5 (complex karyotype), 1 case (5.3\%) with monosomy 5 and 1 case $(5 \%)$ with $5 q-$ (Table 1). Using FISH, $10 / 19$ cases (53\%) were found to have trisomy 8 . In cases with trisomy $8+$ there were 3200 CFCs by FISH compared with only 1720 in trisomy 8- (Table 2).

\section{Survivin expression}

The mean percentage of survivin cells were significantly higher in MDS cases compared with controls $(P<0.05)$ and among trisomy $8+$ MDS cases compared with trisomy $8-$ MDS cases $(P<$ 0.05) (Table 2 and Figure 1). However, no significant correlation was found between the individual values of percentage of survivin + cells and percentage of trisomy $8+$ cells or percentage of CD34+/Annexin+/PI- cells in MDS cases with or without trisomy 8 ( $P>$ 0.05) [data not shown].

\section{Haemopoietic colony cell formation}

The colony-forming cell counts of trisomy $8+$ MDS cases were comparable to those of normal controls and significantly higher than in other high-risk MDS cases $(P<0.05)$. Also significantly lower numbers of CFCs was observed in trisomy 8 - cases than in controls $(P$ $<0.05$ ) (Table 2 and Figure 2). No significant correlation was found between colony formation and the percentage of survivin+ cells or CD34+/Annexin+/ PI- cells $(P>0.05)$ [data not shown]. However, there was a significant positive correlation between colony-forming cell counts and percentage of trisomy $8+$ cells $(P<0.05)$ (Figure 2$)$.

\section{Survival studies}

There was a longer progression-free survival among trisomy $8+$ MDS cases compared with cases with other cytogenetic abnormalities; however the difference was not statistically significant 


\begin{tabular}{|c|c|c|c|c|c|c|}
\hline \multirow[t]{3}{*}{ Parameter } & \multicolumn{2}{|c|}{ High-risk MDS } & \multirow{2}{*}{$\begin{array}{l}\text { Controls } \\
(n=10)\end{array}$} & \multicolumn{3}{|c|}{$\boldsymbol{P}$-values } \\
\hline & $\begin{array}{c}\text { Trisomy } 8+ \\
\text { cases } \\
(n=10)\end{array}$ & $\begin{array}{c}\text { Trisomy 8- } \\
\text { cases } \\
(\boldsymbol{n}=9)\end{array}$ & & $\begin{array}{l}\text { Trisomy } 8+ \\
\text { vs controls }\end{array}$ & $\begin{array}{l}\text { Trisomy 8- } \\
\text { vs controls }\end{array}$ & $\begin{array}{c}\text { Trisomy 8+ } \\
\text { vs 8- }\end{array}$ \\
\hline & Mean (SD) & Mean (SD) & Mean (SD) & & & \\
\hline CD34+/Annexin V+/ PI- cells (\%) & $43.0(24.3)$ & $11.0(6.3)$ & $4.5(3.9)$ & $<0.05$ & $>0.05$ & $<0.05$ \\
\hline Survivin+ cells (\%) & $17.2(16.5)$ & $9.6(3.9)$ & $0.0(0)$ & $<0.05$ & $<0.05$ & $<0.05$ \\
\hline Colony-forming cells (no./culture) & $3200(2150)$ & $1720(1100)$ & $3580(1460)$ & $>0.05$ & $<0.05$ & $<0.05$ \\
\hline Overall survival (months) & $28(9)$ & $18(10)$ & - & - & - & $>0.05$ \\
\hline Progression-free survival (months) & $19(6)$ & $10(6)$ & - & - & - & $>0.05$ \\
\hline
\end{tabular}

$S D=$ standard deviation; $P I=$ propidium iodide .

$(P>0.05)$. The rate of overall survival was also not significantly different comparing trisomy $8+$ and $8-$ MDS cases (Table 2 and Figure 1).

\section{Discussion}

MDS is a pre-neoplastic condition that frequently develops into overt acute leukaemia [21]. Leukaemic transformation has been presumed to be the result of multiple tandem chromosomal lesions and genetic mutations, some affecting cellular proliferation and others conferring resistance to apoptosis [10].
The pathogenesis of MDS is thought to include involvement of the MDS clone itself in abnormal apoptosis, signalling and immune deregulation of the bone marrow microenvironment [22]. One area of active clinical research in the treatment of MDS is the role of disruption of stromal production of the inflammatory cytokines that induce premature apoptosis of bone marrow cellular elements, which in turn contributes to the ineffective haematopoiesis in MDS [23]. However, although initial studies on purified CD34 cells in some MDS cases showed increased numbers of apoptotic cell markers, other investigators have demonstrated that CD34 cells from patients with MDS are resistant to apoptosis [10]. These contradictory reports prompted us to conduct the present study on MDS patients, focusing on high-risk cases, who are more liable to disease progression and poor outcomes, mostly due to leukaemic transformation.

To ensure that our findings regarding apoptosis were not related to differences in cellular differentiation we conducted our research on CD34+ cells. These cells expressed increased

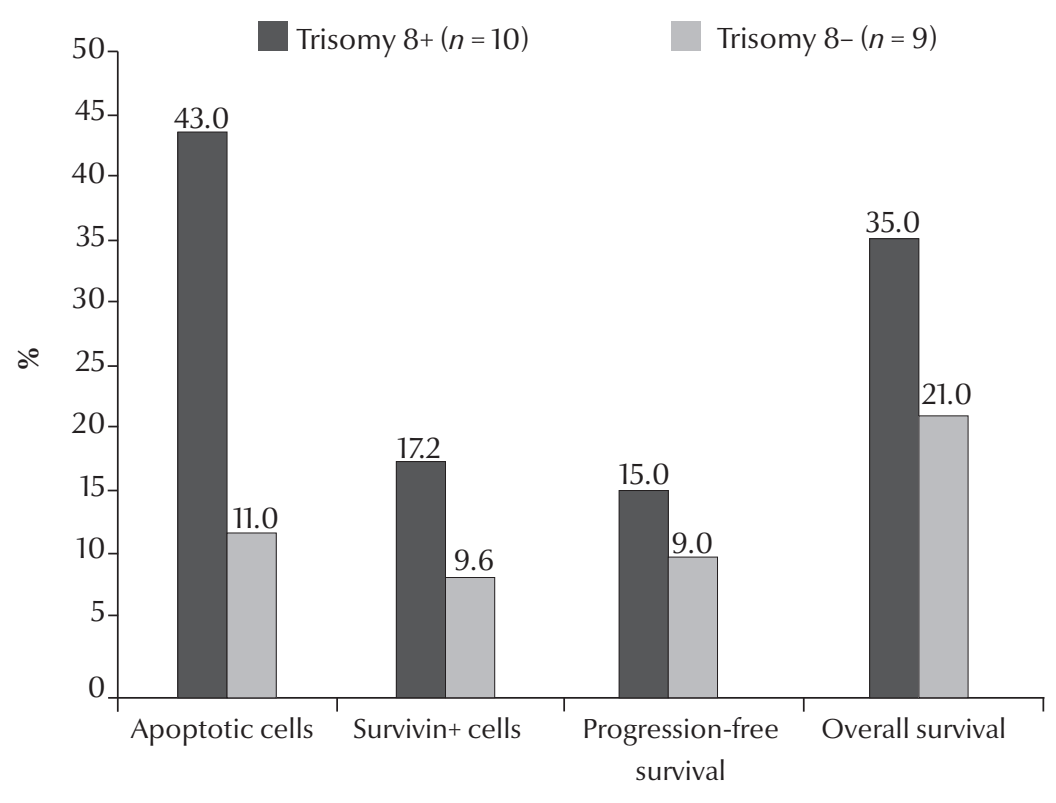

Figure 1 Comparison of apoptosis, proliferation and patient survival rates in cases of high-risk myelodysplastic syndrome characterized as trisomy $8+$ or trisomy 8- 

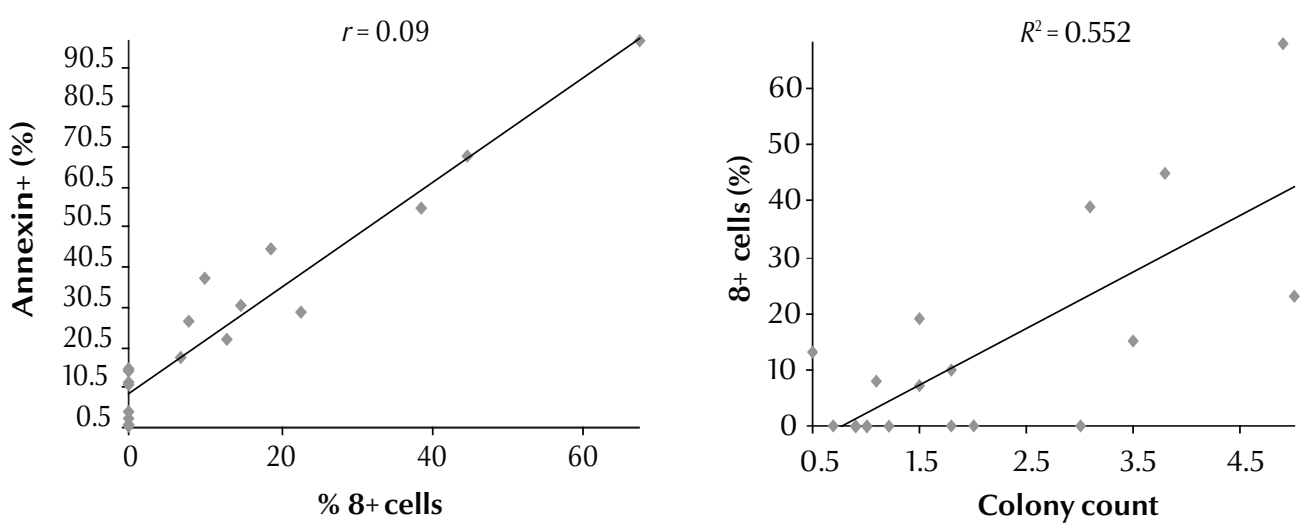

Figure 2 Correlation of trisomy $8+$ cells to apoptosis and capacity for haematopoietic colony formation in high-risk myelodysplastic syndrome cases $(n=19)$

amounts of annexin $\mathrm{V}$ in MDS patients compared with controls and among trisomy 8+ MDS cases compared with other MDS cases and with controls. This confirms previous reports of increased apoptosis among the haematopoietic progenitor cells in MDS patients and an even higher increase among trisomy $8+$ cases. Bone marrow cells from MDS patients with trisomy $8+$ demonstrated significantly higher cell-surface Fas expression and comprised a higher proportion of annexin $\mathrm{V}+/ \mathrm{PI}-$ cells and caspase $3+$ cells compared with cells from other MDS patients, particularly those with monosomy 7 or having a normal karyotype [10].

The findings in previous research that trisomy $8+$ cells are Fas+ and annexin $\mathrm{V}+$ is consistent with a cell population under immune attack and undergoing apoptosis [12]. This was postulated to be due to an immune response directed against neoantigens on trisomy $8+$ cells. In this scenario, activated T-cells in proximity to trisomy $8+$ cells would release cytokines (interferon gamma and tumour necrosis factor-alpha) upregulating apoptotic signals on the surface of haematopoietic cells. This was further confirmed in other studies by the ability of trisomy $8+$ cells to increase their proliferative activity in the absence of an immune response in $\mathrm{T}$-cell depleted samples [10].
Despite the apparent apoptotic activity in our trisomy 8+ MDS cases, the cellular capacity for colony formation was maintained at near normal levels. The increased expression of survivin in these cases could provide the rationale for the anti-apoptotic effect, a findings that concurs with studies demonstrating increased levels of survivin in MDS patients, even those low-risk cases $[7,24]$. Other research has revealed several patterns of aberrantly reduced myeloid nuclear differentiation antigen, which functions to enhance apoptosis induced by tumour necrosis factor-related apoptosis-inducing ligand (TRAIL) in intermediate and high-grade MDS [25]. Research too has shown elevated levels of the antiapoptotic agent NF-KappaB, whose inhibition induced rapid apoptosis of bone marrow cells from high-risk MDS cases [21]. The latter data, which indicate the presence of proliferative activity within MDS clones, is also confirmed by the growth advantage observed in MDS cells particularly those from patients having trisomy 8 , in our study as well as another recent study [10].

The rate of survival of the trisomy 8 cases in our study did not vary significantly from other cases of high-risk MDS, possibly since treatment was not tailored to individual cases and was mostly palliative, pending the availability of bone marrow transplantation in suitable cases.

Recent advances in understanding the pathogenesis of MDS have led to significant therapeutic progress [1]. Currently there is no standard treatment for MDS and, since the aim of therapy is to eliminate the damaged colony-forming units [4], allogenic stem-cell transplantation remains the only curative strategy [22]. The pharmacological treatment provided for patients who cannot qualify for transplantation aims to induce differentiation of haematopoietic cells and also to inhibit apoptosis [4]. New therapeutic options include thalidomide and its analogue lenalidomide, which has proven extremely effective for patients with $5 q$ - syndrome [1]. However, based on the results of the current study and previous work, we strongly believe that in high-risk MDS cases enhanced apoptosis may have a beneficial role in ameliorating the anti-apoptotic activity in these cases and may defer the risk of leukaemic transformation. New DNA hypomethylating agents azacytidine and decitabine have shown efficacy in patients with high-risk MDS and they may delay the disease progression [1]. Novel therapeutic strategies include molecular inhibition of MDS stem cell apoptosis as well as trials to use small-interfering-RNA to knock down survivin [12]. 
Although trisomy $8+$ MDS cases are known to be have intermediate prognosis [3], our study showed a difference in the response to therapy and survival between trisomy $8+$ and 8 - high-risk cases, The fact that this difference was not statistically significant may be attributed to the small size of the sample and warrants further studies of larger samples. The findings of this study, as well as the review of previous work about this topic, provides reasonable evidence that cytogenetic and flow cytometric analysis can help map the profile of different risk groups in MDS. We believe that the prognoses for patients with this disease may be predicted according to the balance of apoptotic and anti-apoptotic activity of their CD34+ bone marrow cells, in conjunction with their cytogenetic analysis, particularly for trisomy 8 cases, since this group of patients seem to stand out as a prognostically separate entity. This information, once available, can facilitate therapeutic decisions for individual patients. We also recommended evaluating the apoptotic/antiapoptotic profile of the newer drugs that are directed against survivin in trisomy $8+$ high-risk MDS cases.

\section{References}

1. Lindberg EH. Strategies for biology and molecular based treatment of myelodysplastic syndromes. Current Drug Targets, 2005, 6:713-725.

2. Morel P et al. Prognostic factors in myelodysplastic syndromes: critical analysis of the impact of age and gender and failure to identify a very low-risk group using standard mortality ratio techniques. British Journal of Haematology, 1996, 94:116-119.

3. Gianelli $U$ et al. Survivin expression in low risk and high-risk myelodysplastic syndromes. Annals of Hematology, 2007, 86:185-189.

4. Homenda W, Peiska M, Kochanowska-Demczyna A. Zespoly mielodysplastyczne--patogeneza i leczenie [Myelodysplastic syndromes-pathogenesis and treatment]. Wiadomosci Lekarskie (Warsaw, Poland), 2005, 58:204-207.

5. Soligo DA, Oriani A, Annaloro C. CD34 immunohistochemistry of bone marrow biopsies: prognostic significance in primary myelodysplastic syndromes. American Journal of Hematology, 1994, 46:9-17.

6. Ogata $\mathrm{K}$ et al. Clinical significance of phenotypic features of blasts in patients with myelodysplastic syndrome. Blood, 2002, 100:3887-3896.

7. Gelsi-Boyer V, Vev N. Avancees dans la prise en charge des syndromes myelodysplasiques [Recent advances in the treat $R$ ment of myelodysplastic syndromes]. La Revue de medecine interne, 2006, 27:600-609.

8. Hofman WK et al. Characterization of gene expression of CD34+ cells from normal and myelodysplastic bone marrow. Blood, 2002, 100:3553-3560.

9. Tehranchi $\mathrm{R}$ et al. Granulocyte colony stimulating factor inhibits spontaneous cytochrome c release and mitochondria-dependent apoptosis of myelodysplastic syndrome hematopoietic progenitors. Blood, 2003, 101:1080-1086.

10. Sloand EM et al. Fas mediated apoptosis is important in regulating cell replication and death in trisomy 8 hematopoietic cells but not in cells with other cytogenetic abnormalities. Blood, 2002, 100:4427-4432.

11. Nevill TJ, Fung HC, Shepherd JD. Cytogenetic abnormalities in primary myelodysplastic syndrome are highly predictive of outcome after allogenic bone marrow transplantation. Blood, 1998, 92:1910-1917.

12. Sloand EM et al. CD34 cells from patients with trisomy 8 myelodysplastic syndrome express early apoptotis markers but avoid programmed cell death by up-regulation of antiapoptotic proteins. Blood, 2007, 109:2399-2405.

13. Maciejewski JP et al. Distinct clinical outcomes for cytogenetic abnormalities evolving from aplastic anemia. Blood, 2002, 99:3129-3135.

14. Bernasconi $\mathbf{P}$ et al. Incidence and prognostic significance of karyotype abnormalities in de novo primary myelodysplastic syndromes on 331 patients from a single institution. Leukemia, 2005, 19:1424-1431.

15. Greenberg P et al. International scoring system for evaluating prognosis in myelodysplastic syndromes. Blood, 1997, 89:2079-2088.

16. Bowen D et al. Guide lines for the diagnosis and therapy of adult myelodysplastic syndromes. British Journal of Haematology, 2003, 120:187.

17. Cheson BD et al. Report of an international working group to standardize response criteria for myelodysplastic syndromes. Blood, 2000, 96:3671.

18. Mitelman F, ed. ISCN 1995. An international system for human cytogenetic nomenclature. Basel, Kargen, 1995.

19. Adida $\mathrm{C}$ et al. Expression and prognostic significance of survivin in de novo acute myeloid leukemia. British Journal of Haematology, 2000, 111:196-203.

20. Miller $\mathrm{CL}$, Eaves $\mathrm{CJ}$. Long term culture initiating cell assay for human and murine cell. In: Klug CA, Jordan CT, eds. Hematopoietic stem cell protocols. Totowa, New Jersey, Humana Press, 2002:123.

21. Briggs RC et al. Dysregulated human myeloid nuclear differentiation antigen expression in myelodysplastic syndromes: evidence for a role in apoptosis. Cancer Research, 2006, 66:4645-4651.

22. Corey SJ et al. Myelodysplastic syndromes: the complexity of stem-cell diseases. Nature Reviews. Cancer, 2007, 7:118-129.

23. Sekeres MA, List A. Immunomodulation in myelodysplastic syndromes. Best Practice \& Research. Clinical Haematology, 2006, 19:757-767.

24. Sun $\mathrm{H}$ et al. [Expression of survivin, Bcl-2 and VEGF in patients with myelodysplastic syndrome and their relationship]. Zhongguo Shi Yan Xue Ye Xue Za Zhi, 2006, 14:271-275 [In Chinese].

25. Braun T et al. NF-KappaB constitutes a potential therapeutic target in high-risk myelodysplastic syndrome. Blood, 2006, 107:1156-1165. 